Akan, M. (2016). Sustainability, consumption, and technology. Copernican Journal of Finance \& Accounting, 5(2), 9-25. http://dx.doi.org/10.12775/CJFA.2016.012

\author{
Mustafa Akan ${ }^{*}$
}

Dogus University

\title{
SUSTAINABILITY, CONSUMPTION, AND TECHNOLOGY
}

Keywords: sustainability, technology, consumption, optimal control theory, economic development, natural resources.

J E L Classification: 01, 02, 03.

Abstract: Sustainability of current economic system is analyzed in the face of growing population, accelerating exploitation of limited natural resources, and advances in technology. A Cobb-Douglas type of production function is assumed. Optimal control theory is employed to model the problem. It is proved that long term sustainability is possible, with or without population growth, only under certain conditions related to production and utility functions of the society.

\section{IIIIRODUCTION}

It is true that the earth has limited resources, and it supports an increasing population who is consuming these resources at an increasing rate. Furthermore, the prevailing economic system (globalized capitalism) is encouraging more consumption. The recent economic crisis which slowed down the growth rate of many nations (especially developed ones) has led all the leaders of these nations to take extraordinary measures to return their economies to reasonable growth rates. However, despite all these measures, the economies of these

Date of submission: December 1, 2016; date of acceptance: January 31, 2017.

* Contact information: mustafaakan1917@gmail.com, Faculty of Economics and Administrative Sciences, Dogus University, Acibadem, Kadikoy, 34722 Istanbul, Turkey, phone: +00905333119405. 
nations are not growing at desired levels even in the United States where these measures have made a significant impact on unemployment.

The world economic crisis which started as a financial crisis in the USA in 2008 has spread over to Europe and the rest of the world. Governments have taken actions to stabilize the financial sector by principally increasing money supply and other measures such as taking over some of the financial institutions affected by the crisis (Skidelsky, 2009). The crisis is continuing in Europe with more significant impact on the economies of Greece, Italy, Portugal, and Spain.

The financial crisis has affected the real sector also in almost all major economies of the World. A recent study by OECD study (Economic Outlook, 2016) estimates that the US will grow only by $2.1 \%$, Euro area OECD countries are expected to grow by $1.8 \%$, the total of OECD countries will grow by $2.0 \%$ and China by $6.1 \%$ in 2017.

The same study estimates that unemployment rate in the USA will be 4.6 while consumer price index will be $1.9 \%$ in 2017. OECD countries will have unemployment rates of $6.1 \%$ in 2017 . Consumer price index for this group is forecasted to be $1.9 \%$ in 2017.The unemployment rate for the total of OECD will remain around $6.1 \%$.

It looks as if the economies of the USA and Europe will grow at a slow pace with low inflation, low interest rates, and high unemployment rates for some time even if the ongoing financial crisis is contained without major interruption. Additional problems such as migration and the exit of UK from the European Union have introduced additional problems.

Thus, it is important for all countries to increase their growth rates to reasonable levels to lower their unemployment rates, or, at least, keep them at their current levels even in the face of important problems in the financial sectors of many of these nations like the USA and significant number of European nations. Monetary policies seem to be ineffective in large economies like the USA and Europe. Very low levels of interest rates do not seem to induce growth enough to make significant reductions in unemployment levels. The Governments of the USA and European union are in search of rules and regulations to put in place to assure the business world's and the customers' confidence for the proper functioning of the markets.

The search, therefore, will be for policies to induce growth even under these conditions for both governments and individual firms as the efforts on the part 
of the governments to stabilize the economic system continue to sustain the current system.

However, almost insatiable desire for growth (more consumption) and the increasing population are already straining the resources of the world including energy, clean air, and water. Climate change and related catastrophic events are almost everyday occurrences. The world's population has increased from 3 billion to 6.9 billion between 1960 and 2012 (World Bank, 2012) and it is expected to reach over 9 billion by 2050 (Meadows, 2004, p. 28).

The energy consumption by time and by type of fuel is given in Table 1 below.

Table 1. Energy consumption by type, time, and estimates for the future (QuadrillionBTU)

\begin{tabular}{|c|c|c|c|c|c|c|c|c|c|c|}
\hline Region/Country & 2005 & 2006 & 2007 & 2008 & 2010 & 2015 & 2020 & 2025 & 2030 & 2035 \\
\hline \multicolumn{11}{|l|}{ Total OECD } \\
\hline Liquids & 100,4 & 99,6 & 99,3 & 96,5 & 91,6 & 94,1 & 95,6 & 96,7 & 97,9 & 99,7 \\
\hline Natural Gas & 53,6 & 54,1 & 55,7 & 56,3 & 56,5 & 59,2 & 61,4 & 63,6 & 67,1 & 70,6 \\
\hline Coal & 46,7 & 46,8 & 47,8 & 46,8 & 43,5 & 42,6 & 43,1 & 44,6 & 45,3 & 46,7 \\
\hline Nuclear & 23,3 & 23,4 & 22,6 & 22,6 & 22,7 & 25,2 & 26,7 & 27,8 & 29,1 & 29,8 \\
\hline Other & 20 & 20,4 & 20,7 & 22,1 & 23,7 & 29,3 & 33,6 & 37,1 & 39,4 & 41,4 \\
\hline Total & 243,9 & 244,3 & 246,1 & 244,3 & 238 & 250,4 & 260,6 & 269,8 & 278,7 & 288,2 \\
\hline \multicolumn{11}{|l|}{ Total Non OECD } \\
\hline Liquids & 70,4 & 72,1 & 73,4 & 76,4 & 81,6 & 93,1 & 100,1 & 110,3 & 118,7 & 125,5 \\
\hline Natural Gas & 51,5 & 53,4 & 55,2 & 58 & 60,1 & 68,1 & 76,6 & 85,9 & 95,2 & 104,1 \\
\hline Coal & 75,6 & 80,4 & 85,6 & 92,2 & 105,9 & 114,7 & 121,4 & 135,1 & 149,4 & 162,5 \\
\hline Nuclear & 4,2 & 4,4 & 4,5 & 4,6 & 5 & 7,9 & 12,2 & 15,8 & 18,3 & 21,4 \\
\hline Other & 25,5 & 26,8 & 27,8 & 29,2 & 31,5 & 39,3 & 48,6 & 54,6 & 61,2 & 68,1 \\
\hline Total & 227,2 & 237,1 & 246,5 & 260,4 & 284,1 & 323,1 & 358,9 & 401,7 & 442,8 & 481,6 \\
\hline \multicolumn{11}{|l|}{ Total World } \\
\hline Liquids & 170,8 & 171,7 & 172,7 & 173 & 173,2 & 187,2 & 195,8 & 207 & 216,6 & 225,2 \\
\hline Natural Gas & 105 & 107,5 & 110,9 & 114,3 & 116,7 & 127,3 & 138 & 149,4 & 162,3 & 174,7 \\
\hline Coal & 122,3 & 127,2 & 133,3 & 139 & 149,4 & 157,3 & 164,6 & 179,7 & 194,7 & 209,1 \\
\hline
\end{tabular}


Table 1. Energy consumption by type, time, and estimates for the future...

\begin{tabular}{|l|c|c|c|c|c|c|c|c|c|c|}
\hline \hline Region/Country & $\mathbf{2 0 0 5}$ & $\mathbf{2 0 0 6}$ & $\mathbf{2 0 0 7}$ & $\mathbf{2 0 0 8}$ & $\mathbf{2 0 1 0}$ & $\mathbf{2 0 1 5}$ & $\mathbf{2 0 2 0}$ & $\mathbf{2 0 2 5}$ & $\mathbf{2 0 3 0}$ & $\mathbf{2 0 3 5}$ \\
\hline \hline Nuclear & 27,5 & 27,8 & 27,1 & 27,2 & 27,6 & 33,2 & 38,9 & 43,7 & 47,4 & 51,2 \\
\hline Other & 45,4 & 47,1 & 48,5 & 51,3 & 55,2 & 68,5 & 82,2 & 91,7 & 100,6 & 109,5 \\
\hline Total & 471 & 481,3 & 492,5 & 504,8 & 522,1 & 573,5 & 619,5 & 671,5 & 721,6 & 769,7 \\
\hline \hline
\end{tabular}

S o u r c e : International Energy Outlook, 2011.

However, the reserves of energy sources (oil, natural gas) and the number of years they will support consumption by humans are 65, and 50-75 years respectively (Meadows, 2004). Renewable energy, even though it receives considerable attention, constitutes only $10 \%$ of the total energy requirement as of 2013.

Consumption of five important metals is increasing at an increasing rate (Meadows, 2004, p. 101). Consumption of steel exhibits the same behavior (Meadows, 2004, p. 101). Estimates of life expectancy of identified reserves of major metals are presented in Meadows (2004, p. 105).They range from 20 years for zinc to 81 years for aluminum.

The problem of climate change, now visible to residents of the earth, is summed up by 6 Nobel laureates (Meadows, 2004, pp. 115-117) as "the balance of evidence suggests a discernible human influence on global climate. As economists, we believe that global climate change carries with it significant environmental, economic, social, and geopolitical risks, and that preventive steps are justified". Meadows et al. (2004, p. 115) showed that carbon dioxide, methane, nitrous oxide, and chlorofluorocarbons emissions have increased very sharply in past few decades. Rising temperature of the earth and the economic losses from weather related disasters are shown to be drastic in Meadows (2004, pp. 116-117).

Fresh water problem is already an important problem. A UN Report (1997) states: “...current pathways for fresh water use are often not sustainable... water degradation are weakening one of the resource base on which human society is built".

Forests, lungs of the earth, are, like water, is already a problem also especially in the light of air pollution problem. World Commission on Forests and Sustainable Development in their report (1999) comes to the conclusion that: "... a trend toward a massive loss of forested areas... and all is threatened". 
Decrease in the amount of cultivable land, clean air (air pollution), extinction of some members of fauna and flora are other important losses that human consumption is causing.

All these problems on which some data are provided clearly raise the question of sustainability of the current economic system based on increasing consumption.

Sustainability is defined as: "a sustainable society is one that meets the needs of the present without compromising the ability of future generations to meet their own needs" in Meadows et al. (2004, p. 254). It is defined as the ability of, at least, maintaining the current level of well-being for future periods or future generations in Stiglitz et al. (2010, p. 97). Arrow et al. (2004, p. 150) defined sustainability as the ability to maintain a non-decreasing social welfare through time. Pezzey and Toman (2002, p. 24) has reviewed the journal articles on sustainability and concluded that: "the dearth of empirical work on what sustainability might mean for environmental and economic valuations, and the continued lack of concrete understanding of what sustainability policies might entail in practice, indicate the scale of continual intellectual challenges in the field". Chichilnisky (1997) developed axioms that capture the idea of sustainability and characterize the welfare criteria that they imply. Chichilnisky et al. (1995) introduced a growth model with environmental assets as source of utility and an input to consumption and production. They developed a Golden Rule as a generalization of neoclassical growth theory. Marsiglio (2011) studied the relationship between population growth and economic growth through the study of fertility choices and concluded that a sustainable path can be found if stationary fertility rate is higher than the mortality rate. Azamamahou et al. (2014), Boucekkini et al. (2014) and Constant et al. (2014) have all studied the relationship between growth, population and pollution.

Tim Jackson (2009) has proposed steps for transition to a sustainable economy. Lester Brown (2009) has also outlined the actions to take to make a transition to sustainable economy.

As reasonable as these steps (actions) might be, their implementation is difficult due to the strength of current consumption culture, strength of parties(firms and consumers who are raised within the consumption culture) to oppose such changes, and different political considerations by different nations, etc.

Technology or technological development stands as one area where significant gains can be obtained for transition to sustainable economies. 
Technology is defined as: "society's pool of knowledge regarding the industrial arts" in Mansfield (1971, p. 9). Mansfield adds: "technology consists of knowledge used by industry regarding the principles of physical and social phenomena... knowledge regarding the application of these principles to production... and knowledge regarding the day to day operations of production...". In the same study, Mansfield also states that $90 \%$ of increase in output per capita in the USA is attributable to technological change. Oliner (2002) showed that labor productivity in the USA after 1995 was largely due to advances in IT technology. Gordon (2002) also showed that technological acceleration, particularly in information technology, was responsible for the American miracle of 1995-2000. Jorgenson et al. (2008) also concludes that: "the USA should be well positioned to innovate and benefit as improved technologies emerge". McKinsey \& Company (2009) has shown that $80 \%$ of growth in the USA between 2000 and 2008 was due to productivity increase. McKinsey \& Company (2013) has shown that the productivity growth during 1995-2000 occurred in retail, wholesale, semiconductor, computer manufacturing, telecommunications, securities, and banking sectors and most of this growth was due to technological advances. Sachs and McArthur (2002) also conclude that technological advances are almost certainly the driver of long term economic growth. Porter, Sachs, and McArthur (2002) showed that there was a very strong correlation between Growth Competitiveness Index (GCI) and Technology Index Rank. Nelson (1996) in a book of collected papers on growth and technology reaches the same conclusion that technological advance is the key driving force in economic growth. All these selected studies clearly show that the advances in technology have a determining impact on growth.

\section{RESEARCH METHODOLOGY AND RESEARCH PROCESS}

In this study, we will build on definitions introduced by Arrow et al. (2004) to develop a mathematical model taking into consideration the interrelation between natural resources, technology (defined as the productive base), and consumption.

Productive base is defined in Arrow et al. (2004, p. 149) as: "society's capital assets and institutions at a given time. The capital assets include manufactured capital, human capital and natural capital. The productive capital also includes the knowledge base and society's institutions..." which will be named as technology base, or just technology throughout this paper. 
We will assume that the manufactured capital, as its name applies, is an output itself since any such capital is manufactured by use of technology, labor, and natural capital i.e. manufactured capital is a function of natural capital, labor and technology. We will also assume that labor (population) grows at a certain rate hence it is assumed to be an exogenous variable. Natural capital is actually the limited resources of the earth which declines by the rate of their usage (extraction rate). These assumptions change the definition of productive base to 'technology base'. Another definition by Arrow et al. is the 'genuine investment' which refers to the change in the productive base which, in this paper, implies change in the technology base and the change in the natural resource base.

The objective of the society is given as the present value of the utility of consumption discounted by a given social discount factor (social welfare function as defined by Arrow et al.). Then, the questions to be answered are:

- How much should consume over an infinite horizon?

- What should be the extraction rate of natural resources?

In order to maximize the social welfare function given that the reserves of natural capital is fixed or can be increased only by technology.

A mathematical model is presented in the next section. The model will be solved in the third section followed by the conclusions and suggestions for further research.

\section{THE MODEL AND ITS SOLUTION}

The objective of the society is to maximize the sum of its discounted utility over an infinite horizon where the utility of consuming an amount $\mathrm{c}(\mathrm{t})$ at time $\mathrm{t}$ is represented by $\mathrm{u}(\mathrm{c}(\mathrm{t}))$. The discount factor is represented by $\mathrm{e}-\rho t$ where the letter $\rho$ is the social discount factor.

The productive base is split into two because of the differences in their dynamics. The natural resource base $\mathrm{R}(\mathrm{t})$ decreases by the extraction rate $\mathrm{z}(\mathrm{t})$, increases by the new discoveries of reserves and renewable sources made possible by technology base, $\mathrm{T}(\mathrm{t})$.

Mathematically (skipping the variable $t$ in the related variables):

$$
\begin{aligned}
& R^{\prime}=-z+\eta T^{\mu} \\
& R(0)=R_{0}
\end{aligned}
$$


which denotes the starting reserve level of natural resources. The parameters $\mu$ and $\eta$ represent the positive impact of technology on natural resource base.

The labor, as the other resource base, behaves differently than natural resource base. It is assumed to increase at a constant exponential rate g. i.e.:

$$
L(t)=L(0) e^{g t}
$$

The manufactured capital is a product of technology, natural resources, and labor i.e. an intermediary product where:

$$
K(t)=f(T(t), z(t), L(t))
$$

The production function of the society which can be generally written as a function of manufactured capital $\mathrm{K}$, labor $\mathrm{L}$, resource extraction $\mathrm{z}$ and the technology base $\mathrm{T}$ as:

$$
\begin{aligned}
& Y=F(K(t), L(t), Z(t), T(t)) \text { which can be rewritten as: } \\
& Y=F(T(t), z(t), L(t)) .
\end{aligned}
$$

Given above definitions and dynamics of natural resources and labor, the other most important productive base component is technology. The dynamics related to technology is given as:

$$
T^{\prime}=T^{\alpha} z^{\gamma} L^{\beta}-L_{0} c e^{g t}-k T=T^{\alpha} z^{\gamma}\left(L_{0} e^{g t}\right)^{\beta}-L_{0} c e^{g t}-k T
$$

$T(0)=T_{0}$ which denotes the level of technology at $\mathrm{t}=0$.

The first term on the right hand side of this equality shows the total production of the society as a combination labor, technology, and natural resources (a Cobb Douglas type of production function is assumed). The total production is allocated to consumption (the second term on the right hand side of the equation) and improving the level of technology as a productive base ( $\left.\mathrm{T}^{\prime}\right)$, and technological obsolescence represented by kT term where k represents the exponential rate of obsolescence rate of technology.

Then, the model in an optimal control theoretic format is: 
$\operatorname{Max} \int_{0}^{\infty} e^{-\rho t} e^{g t} L_{0} u(c) d t$.

Subject to constraints in equations (1)-(3).

Where the utility function is assumed to have the functional form of:

$u(c)=c^{\theta}$ with $\theta<1$.

The Hamiltonian of the system is:

$H=e^{-\rho t} e^{g t} L_{0} u(c)+\lambda_{1}\left(-z+\eta T^{\mu}\right)+\lambda_{2}\left(T^{\alpha} z^{\gamma}\left(L_{0} e^{g t}\right)^{\beta}-L_{0} c e^{g t}-k T\right)$.

The necessary conditions are:

$$
\begin{aligned}
& H_{c}=e^{-\rho t} \theta c^{\theta-1}-\lambda_{2}=0 \\
& H_{z}=-\lambda_{1}+\lambda_{2} T^{\alpha} \gamma z^{\gamma-1} L_{0}^{\beta} e^{g \beta t}=0 \\
& \lambda_{1}^{\prime}=0 \\
& \lambda_{2}{ }^{\prime}=\lambda_{2} k-\left(\lambda_{1} \eta \mu T^{\mu-1}+\lambda_{2} \alpha T^{\alpha-1} \gamma^{\gamma} L_{0} e^{g \beta t}\right)
\end{aligned}
$$

in addition to constraints in equations (1)-(3).

Observing that $\lambda_{1}=$ constant from equation (6), and using the value of $\lambda_{2}$ from equation (4) in equation (5), we can solve $\mathrm{z}$ in terms of $\mathrm{c}$ and T. Substituting this value of $\mathrm{z}$ in equations (1) and (3), we get:

$$
\begin{aligned}
& T^{\prime}=T^{\alpha /(1-\gamma)} c^{(1-\theta) \gamma /(\gamma-1)} D(t)-L_{0} c e^{g t}-k T \\
& \theta(\theta-1) c^{\theta-2} c^{\prime}=\theta c^{(\theta-1)}(\rho+k)-\left[A(t) T^{\mu-1}+B(t) c^{(1-\theta) /(\gamma-1)} T^{(1-\alpha-\gamma) /(\gamma-1)}\right]
\end{aligned}
$$

where $\mathrm{D}(\mathrm{t}), \mathrm{A}(\mathrm{t})$, and $\mathrm{B}(\mathrm{t})$ are known functions of time where:

$$
\begin{aligned}
& \mathrm{D}=\left(\lambda_{1} / \gamma L_{0} e^{g \beta t-\rho t}\right)(1 / \theta)^{\gamma /(\gamma-1)} L_{0} e^{g \beta t}=\left(\lambda_{1} / \gamma\right)(1 / \theta)^{\gamma /(\gamma-1)} \text { if } g \text { and } \rho \text { are zero } \\
& \mathrm{D}(\mathrm{t})=(1 / \theta)^{\gamma /(\gamma-1)}\left(\lambda_{1} / \gamma\right) e^{\rho t} L_{0} \text { if } \rho \text { is not zero. } \\
& \mathrm{A}=\lambda_{1} \eta \mu=\text { constant }
\end{aligned}
$$


$\mathrm{B}=\left(\lambda_{1} / \gamma L_{0} e^{g \beta t}\right)^{\gamma /(\gamma-1)}(1 / \theta)^{1 /(\gamma-1)} L_{0} e^{g \beta t}=\left(\lambda_{1} / \gamma\right)^{\gamma / \gamma-1}(1 / \theta)^{1 / \gamma-1} L_{0}^{1 / 1-\gamma}$ if $\mathrm{g}$ and $\beta$ are zero.

$\mathrm{B}(\mathrm{t})=\left(\lambda_{1} / \gamma\right)^{\gamma / \gamma-1}(1 / \theta)^{1 / \gamma-1} L_{0}^{1 / 1-\gamma} e^{g \beta t /(1-\gamma)}$ if g is not zero.

The system differential equation system above is a nonlinear, first order, nonhomogeneous, system of differential equations the solution of which is difficult. Phase diagrammatic analysis will be employed to study the behavior of this system for $\mathrm{g}=\rho=0$ and for $\mathrm{g}, \rho \neq 0$.

\section{CASE A: $G=P=0$}

This case makes the system easier to analyze since it becomes a homogeneous system. This assumption makes $\mathrm{D}(\mathrm{t}), \mathrm{A}(\mathrm{t})$, and $\mathrm{B}(\mathrm{t})$ all constants as shown above.

Then the system becomes:

$$
\begin{aligned}
& T^{\prime}=T^{\alpha /(1-\gamma)} c^{(1-\theta) \gamma /(\gamma-1)} D-L_{0} c-k T \\
& \theta(\theta-1) c^{\theta-2} c^{\prime}=\theta c^{(\theta-1)} k-\left[A T^{\mu-1}+B c^{(1-\theta) /(\gamma-1)} T^{(1-\alpha-\gamma) /(\gamma-1)}\right] .
\end{aligned}
$$

Leaving c' alone,

$$
c^{\prime}=c k /(\theta-1)-\left[A T^{\mu-1} c^{2-\theta} / \theta(\theta-1)+B c^{((2-\theta) \gamma-1) /(\gamma-1)} T^{(1-\alpha-\gamma) /(\gamma-1)} / \theta(\theta-1)\right]
$$

which is a nonlinear homogeneous system of differential equations. Letting:

$$
\begin{aligned}
& s=\alpha /(1-\gamma)<0 \\
& l=(1-\theta) \gamma /(\gamma-1)<0 \\
& \mathrm{~m}=\mu-1<0 \\
& \mathrm{n}=2-\theta>0 \\
& p=((2-\theta) \gamma-1) /(\gamma-1)<0 \\
& \mathrm{q}=(1-\alpha-\gamma) /(\gamma-1)<0 .
\end{aligned}
$$

In addition, for simplification, let:

$$
\begin{aligned}
& \mathrm{a}=\mathrm{k} /(\theta-1)<0 \\
& \mathrm{~b}=\mathrm{A} / \theta(\theta-1)<0
\end{aligned}
$$


$\mathrm{d}=\mathrm{B} / \theta(\theta-1)<0$
$\mathrm{D}=\left(\lambda_{1} / 2\right)(1 / \theta)^{\gamma /(\gamma-1)} \mathrm{L}_{0}>0$.

The system becomes:

$$
\begin{aligned}
& T^{\prime}=D T^{s} c^{l}-L_{0} c-k T \\
& c^{\prime}=a c-b T^{m} c^{n}-d c^{p} T^{q}
\end{aligned}
$$

This system does not have a closed form solution. Phase Diagrammatic Analysis will be used to characterize the optimal solution.

The loci of points where $T^{\prime}=0$ and $c^{\prime}=0$ are:

$$
\begin{aligned}
& D T^{s} c^{l}-L_{0} c-k T=0 \\
& a-b T^{m} c^{n-1}-d c^{p-1} T^{q}=0 \text { and } \mathrm{c}=0
\end{aligned}
$$

from equations (8) and (9).

However, these loci may or may not intersect depending on the parameters. They may intersect at one or more points also. Five possible forms of the phase diagrams are shown in the appendix. Stability analysis will be considered before the analysis of these phase diagrams.

Linearizing the system (equations 8 and 9) using Taylors expansion:

$$
\begin{aligned}
& T^{\prime}=\left(l D T^{s} c^{l-1}-L_{0}\right)\left(c-c_{s}\right)+\left(D s T^{s-1} c^{l}-k\right)\left(\mathrm{T}-\mathrm{T}_{s}\right) \\
& c^{\prime}=\left(a-n b T^{m} c^{n-1}-d p c^{p-1} T^{q}\right)\left(c-c_{s}\right)+\left(-b m T^{m-1} c^{n}-d c^{p} q T^{q-1}\right)\left(\mathrm{T}-\mathrm{T}_{s}\right)
\end{aligned}
$$

For simplicity, we will rewrite these equations as:

$$
\begin{aligned}
& T^{\prime}=C_{1}\left(c-c_{s}\right)+C_{2}\left(T-T_{s}\right) \\
& \mathrm{c}^{\prime}=\mathrm{C}_{3}\left(c-c_{s}\right)+C_{4}\left(T-T_{s}\right) .
\end{aligned}
$$

Where the capital Cs represents the terms multiplying $\left(\mathrm{c}-\mathrm{c}_{\mathrm{s}}\right)$ and $\left(\mathrm{T}-\mathrm{T}_{\mathrm{s}}\right)$ where $\mathrm{C}_{1}, \mathrm{C}_{2}, \mathrm{C}_{4}$ are all negative. The sign of $\mathrm{C}_{3}$ is ambiguous. For this system to have a saddle point at the intersections of the loci, it is necessary to have:

$$
C_{1} C_{4}-C_{3} C_{2}<0 \text { or } \mathrm{C}_{3} C_{2}>C_{1} C_{4}>0 \text {. }
$$

However, because of the signs of these constants, it is necessary to have 
$\mathrm{C}_{3}<0$ for equation (16) to hold.

Using equations (10) and (11), we find, if equation (17) holds:

$d T / d c=-C_{3} / C_{4}<0$ along $\mathrm{c}^{\prime}=0$ locus at the equilibrium point, $\mathrm{dT} / \mathrm{dc}=-\mathrm{C}_{1} / \mathrm{C}_{2}<0$ along $\mathrm{T}^{\prime}=0$ locus.

These results imply that the stability of equilibrium is possible only on the declining portions of the loci. However, equation (16) must still be satisfied.

From the analysis of the phase diagrams in appendix we can deduce the following:

- Phase Diagram I: No equilibrium exists.

- Phase Diagram II: There is unstable equilibrium since the first condition in equation (18) is not met.

- Phase Diagram III: The equilibrium is not stable since at that point we have;

$d T / d c=-C_{3} / C_{4}$ along $c^{\prime}=0>\mathrm{dT} / \mathrm{dc}=-\mathrm{C}_{1} / C_{2}$ along $\mathrm{T}^{\prime}=0$ which implies that

$C_{1} C_{4}-C_{3} C_{2}>0$ which is contrary to inequality (16), necessary condition for a saddle point.

- Phase Diagram IV: The equilibrium point 2 is a saddle point just as in previous case since at the point we have;

$C_{1} C_{4}-C_{3} C_{2}<0$ which is the inequality (16), the necessary condition for a saddle point.

The other equilibrium points are not saddle points.

- Phase Diagram V: Equilibrium point 1 is stable due to analysis for phase diagram IV. First requirement in equation (18) is not met for equilibrium point 2.

In all of the phase diagrams where there is a saddle point equilibrium the starting level of technology $\left(\mathrm{T}(0)=\mathrm{T}_{0}\right)$ defines the optimal behavior of the system. It will be optimal to start in quadrant $V$ (quadrants are indicated only on phase diagram $V$ ) with a low level of consumption if $\mathrm{T}(0)$ is smaller than the desired S-S level of technology $\left(\mathrm{T}_{\mathrm{s}}\right)$, gradually increasing the consumption until the desired level of technology is reached. This implies that the current generations have to forego large consumptions levels to invest in technology so that 
future generations can produce and consume. The optimal path defined as such may not exist if the consumption level implied by this solution is below the minimum consumption level of humans to continue to exist.

Figure 1. Phase Diagram V

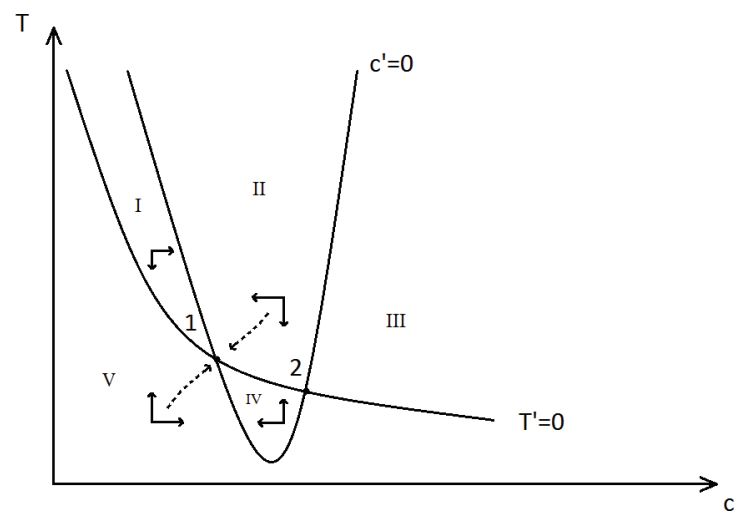

S o u r c e : developed by the author.

It will be optimal to start in quadrant II with a high level of consumption and gradually decrease it to the desired long term level ( $\mathrm{c}_{\mathrm{s}}$ ) if the starting level of technology is higher than the required level in the long run. Starting in other quadrants will not have convergent solutions.

\section{CASE B: G AND P ARE NOT ZERO}

The system in equations (8) and (9) now becomes

$$
\begin{aligned}
& T^{\prime}=(1 / \theta)^{\gamma /(\gamma-1)}\left(\lambda_{1} / \gamma\right) e^{\rho t} T^{s} c^{l}-L_{0} e^{g t} c-k T \\
& c^{\prime}=a c-b T^{m} c^{n}-\left(\lambda_{1} / \gamma\right)^{\gamma / \gamma-1}(1 / \theta)^{1 / \gamma-1} L_{0}^{1 / 1-\gamma} e^{g \beta t /(1-\gamma)} / \theta(\theta-1) \mathrm{c}^{p-1} T^{q}
\end{aligned}
$$

The loci associated with this system are not stationary. Both locus moves leftwards and downwards(towards the origin) as t increases implying that the equilibrium points, if any exists and if stable, results in a lower consumption and lower technology levels than in stationary case( $\rho$ and $g$ are both zero). These consumption levels may not be sufficient for survival. 


\section{IMPLICATIONS AND SUGGESTIONS FOR FURTHER RESEARCH}

- The current system (consumption based economy) may not sustainable if population keeps growing even if there is a long run stable equilibrium.

- The only possible path to sustainable equilibrium is to consume less and to invest more in technology even if population remains stable. Transfer of technology from richer nations (high consumption) to poorer nations (low consumption) becomes a critical policy question.

- The efforts for effective use of technologies such as solar, wind, hydro energy, shale gas, energy conservation, recycling, etc. must be increased to improve the natural resource base. Investment in these areas must be encouraged. Education in basic sciences must be intensified to improve the technology base.

- The model is based on a Cobb-Douglas type of production function. The model can also be solved using CES type of production model and a different type of utility function.

- The model can be solved by putting a lower and an upper limit to consumption.

- The model may be revised to include pollution. 
Appendix: Various Forms of $\mathrm{T}^{\prime}=0$ and $\mathrm{c}^{\prime}=0$ loci



Phase Diagram I

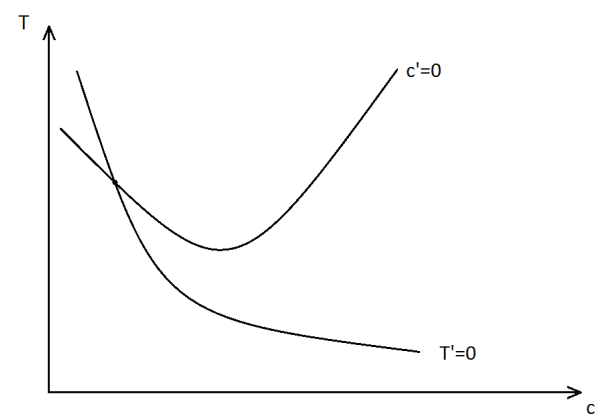

Phase Diagram III

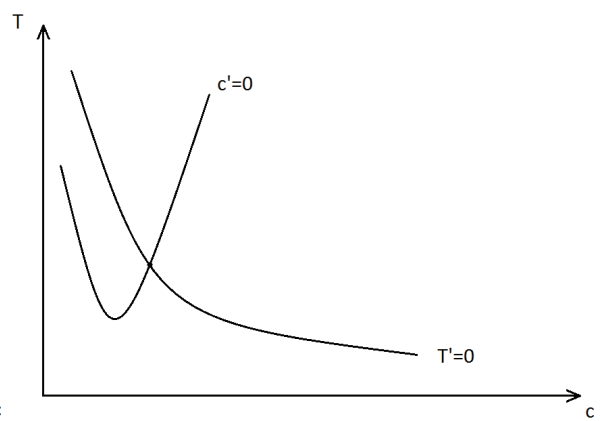

Phase Diagram II

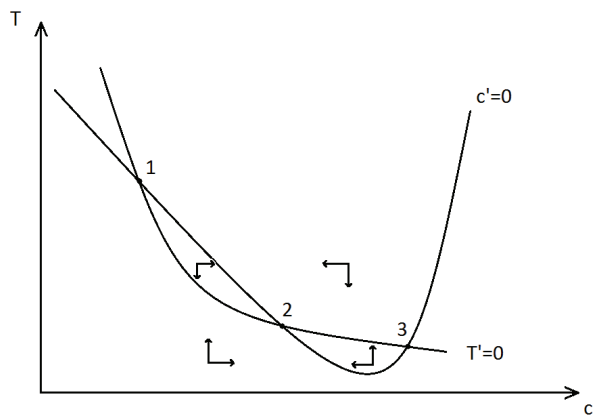

Phase Diagram IV

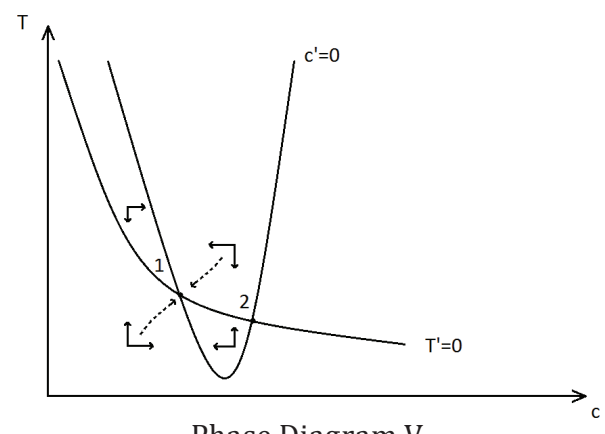

Phase Diagram V 


\section{REFERENCES}

Arrow, K., Dasgupta, P., Goulder, L., Daily, G., Ehrlich, P., Heal, G., Levin, S., Maler, K.G., Schneider, S., Starrett, D., \& Walker, B. (2004). Are we consuming too much? Journal of Economic Perspectives, 18(5), 147-172. doi: http://dx.doi.org/10.1257/0895330042162377.

Azomahou, T.T., Mishra, T., Parhi, M. (2014). Economic growth under stochastic population and pollution shocks. Manchester Business School, Forthcoming.

Brown, L. (2009). Plan B 4.0-Mobilizing to Save Civilization. W.W.Norton.

Boucekkine, R., Martinez, B., \& Ruiz-Tamarit, R. (2014). Optimal sustainable policies under pollution ceiling: the demographic side. Mathematical Modeling of Natural Phenomena, 9(4), 38-63. doi: http://dx.doi.org/10.1051/mmnp/20149404.

Chichilnisky, G. (1997). What is a sustainable development? Land Economic, 73(4), 476-491. doi: http://dx.doi.org/10.2307/3147240.

Chichilnisky,G., Heal,G., \& Beltratti, A. (1995). The Green Golden Rule. Economic Letters, 49, 174-179. doi: http://dx.doi.org/10.1016/0165-1765(95)00662-Y.

Constant, K., Nourryb, C., \& Seegmuller, T. (2014). Population growth in polluting industrialization. Resource and Energy Economics, 36, 229-247. doi: http://dx.doi. org/10.1016/j.reseneeco.2013.05.004.

Gordon, R.J. (2002). Technology and Economic Performance in the American Economy. NBER.

Hestenes, M.R. (1966). Calculus of Variations and Optimal Control Theory. New York: Wiley.

International Energy Outlook (2011).

Jackson, T. (2009). Beyond Growth Economy. Journal of Industrial Ecology, 13(4). doi: http://dx.doi.org/10.1111/j.1530-9290.2009.00151.x.

Jorgenson, D.W., Ho, M.S., \& Stiroh, K.J. (2008). A Retrospective Look at the U.S. Productivity Growth Resurgence. Journal of Economic Perspectives, 22(1), 3-24. doi: http://dx.doi.org/10.1257/jep.22.1.3.

Mansfied, E. (1971). Technological Change, Norton.

Marsiglio, S. (2011). On the relationship between population change and sustainable development. Research in Economics, 65, 353-364. doi: http://dx.doi.org/10.1016/j. rie.2011.01.007.

McKinsey Global Institute (2013). US Productivity Growth.

McKinsey Global Institute (2009). Growth and Renewal in the United States: Retooling America's Economic Engine.

McArthur, J.W. (2002). Competiveness and Stages of Economic Development. World Economic Forum.

Meadows, D., Jorgen, R. (2004). Limits to Growth, The thirty-year update. Chelsea Green.

Nelson, R.R., (1996). The Sources of Economic Growth. Wiley Online Library.

OECD Economic Outlook Report (2011). No: 90.

Oliner, S.D. (2002). Information Technology and Productivity: Where Are We Now and Where Are We Going?. Federal Reserve Bank. 
Porter, M.E., Sachs, J.D., Peterson Silver, E.A. (1979). Decision Systems for the Inventory Management and Production Planning. New York: John Wiley Sons Inc.

Pezzey, C.V., \& Toman, M.A. (2002). The Economics of Sustainability: A Review of Journal articles. Resources for the Future, January.

Sachs, J.D., \& McArthur, J. M. (2002). Technological Advancement and long-term Economic growth in Asia. Speech by J.D. Sachs at Hong Kong University, May.

Skidelsky, R. (2009). Keynes: the return of the master. PublicAffairs.

Stiglitz, J.E., Sen, S., Fitoussi, J.P. (2010). Mismeasuring Our Lives The New Press.

UN Comprehensive Assessment of the Fresh Water Resources (1997).

World Bank (2012). World Bank Data, http://databank.worldbank.org (accessed: 03.01.2015).

World Commission on Forests and Sustainable Development (1999). 
